\title{
Spontaneous Multiple Tendon Rupture in a Hemodialysis Patient
}

\author{
Yan Song, Jianyong Wu and Jianghua Chen
}

Key words: spontaneous tendon rupture, hemodialysis

(Intern Med 53: 1583, 2014)

(DOI: 10.2169/internalmedicine.53.1869)
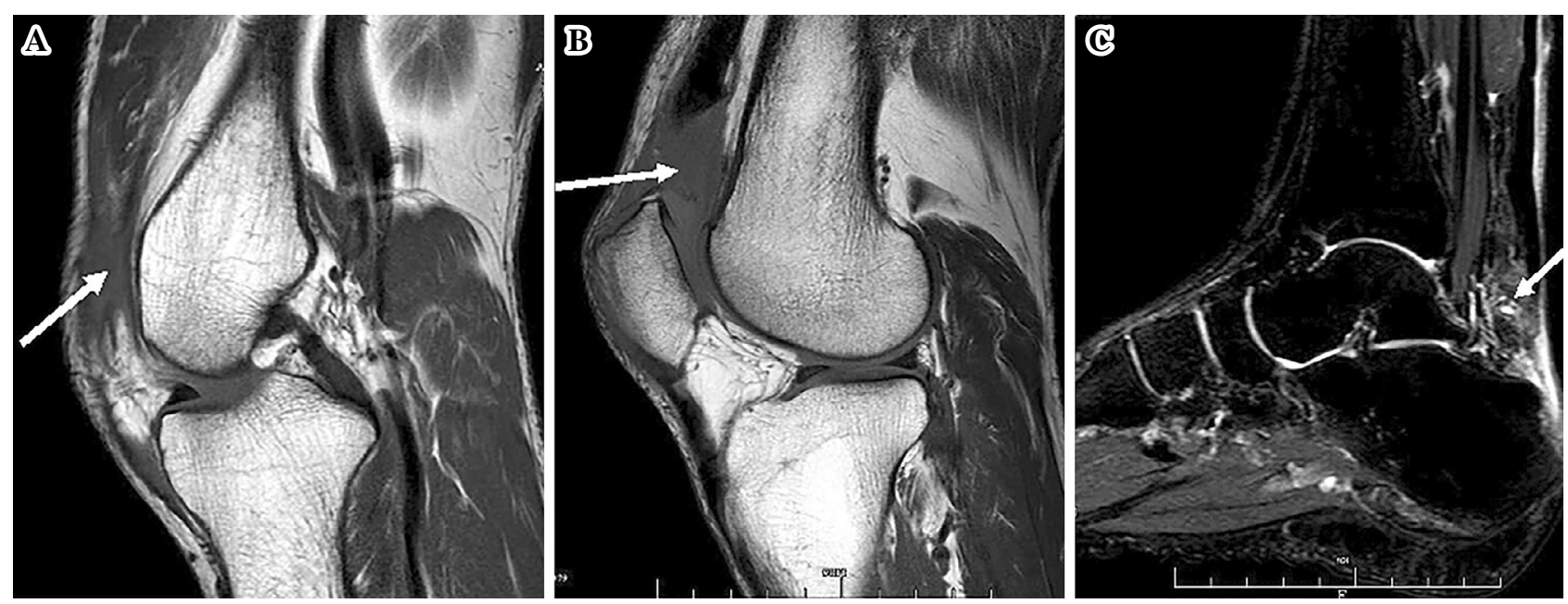

Picture.

A 38-year-old man complained a sudden onset of painful disability of both knees and the left ankle. He denied suffering from any trauma prior to the onset of the joint pain. He had been receiving maintenance hemodialysis for 11 years for end-stage renal disease. A physical examination revealed fixed, firm masses with tenderness over the bilateral quadriceps tendon and Achilles region. A blood gas analysis showed metabolic acidosis, with an arterial blood $\mathrm{pH}$ value of 7.24. The blood urea nitrogen and serum creatinine levels were increased to $25.8 \mathrm{mmol} / \mathrm{L}$ (normal range: $2.9-8.2$ $\mathrm{mmol} / \mathrm{L}$ ) and 1,215 umol/L (normal range: 59-104 umol/L), respectively. The serum phosphate level was $3.27 \mathrm{mmol} / \mathrm{L}$ $(0.87-1.45 \mathrm{mmol} / \mathrm{L})$ and the serum intact parathyroid hormone level was $2,500 \mathrm{pg} / \mathrm{mL}(12-65 \mathrm{pg} / \mathrm{mL})$. The serum level of calcium was normal. Radiographs and MRI of both knees demonstrated the complete rupture of the bilateral patellar and Achilles tendons (Picture A-C, arrows). Following surgical repair, both knees were immobilized in a fixed brace in extension for four weeks, after which the patient became progressively better able to move. Both knees recovered a full range of motion within an eight-month period.

Simultaneous, multiple and spontaneous tendon rupture is a very rare complication in end-stage chronic kidney disease patients $(1,2)$. Long-term hemodialysis, hyperparathyroidism and metabolic acidosis may be involved in the pathogenesis of uremic tendinopathy $(1,2)$.

The authors state that they have no Conflict of Interest (COI).

\section{References}

1. Park JH, Kim SB, Shin HS, Jung GH, Jung YS, Rim H. Spontaneous and serial rupture of both Achilles tendons associated with secondary hyperparathyroidism in a patient receiving long-term hemodialysis. Int Urol Nephrol 45: 587-590, 2013.

2. Basic-Jukic N, Juric I, Racki S, Kes P. Spontaneous tendon ruptures in patients with end-stage renal disease. Kidney Blood Press Res 32: 32-36, 2009.

Kidney Disease Center, the First Affiliated Hospital, College of Medicine, Zhejiang University, China

Received for publication October 7, 2013; Accepted for publication October 10, 2013

Correspondence to Dr. Jianghua Chen, chenjianghua@zju.edu.cn

(C) 2014 The Japanese Society of Internal Medicine Journal Website: http://www.naika.or.jp/imonline/index.html 